\title{
Bem-estar do trabalhador: estudo de caso em instalações para suínos
}

\author{
The welfare of workers: case study in swine housing
}

\author{
Carlos Augusto de Paiva Sampaio ${ }^{[a]}$, Irenilza de Alencar Nääs ${ }^{[b]}$, Douglas D’Alessandro Salgado ${ }^{[c]}$ \\ [a] Engenheiro agrícola, professor associado do Centro de Ciências Agroveterinárias da Universidade do Estado de Santa Catarina \\ (CAV/UDESC), Lages, SC - Brasil, e-mail: a2caps@cav.udesc.br \\ [b] Engenheira civil, professora titular da Faculdade de Engenharia Agrícola da Universidade Estadual de Campinas (FEAGRI/ \\ UNICAMP), Campinas, SP - Brasil, e-mail: irenilza@feagri_unicamp.br \\ [c] Estatístico, professor da Pontifícia Universidade Católica de Campinas (PUC-Campinas), Campinas, SP - Brasil, e-mail: \\ overdoug@yahoo.com.br
}

\section{Resumo}

O objetivo deste trabalho foi determinar o tempo médio de permanência do trabalhador no espaço de produção de suínos e avaliar o conforto térmico para os trabalhadores envolvidos nestas atividades. Nas instalações avaliadas, os resultados mostraram que os trabalhadores permanecem em média 4 horas/dia no espaço do animal para as práticas, principalmente de arraçoamento e limpeza das instalações, e a outra metade do tempo em atividades como transporte de ração e deslocamentos internos. A Temperatura Efetiva não superou o valor permitido, ficando entre $18,9^{\circ} \mathrm{C}$ e $25,6^{\circ} \mathrm{C}$, e a tolerância ao calor medido pelo Índice de Bulbo Úmido e Temperatura de Globo (IBUTG) não foi ultrapassado no período mais desfavorável da jornada de trabalho, conforme legislação brasileira.

Palavras-chave: Fatores ambientais. Trabalhador. Instalações. Suínos.

\begin{abstract}
The objective of this work was to determine the average time of worker's permanence during this daily journey in swine housing and also was also evaluated the environmental thermal comfort of the workers involved in these activities. In the housing evaluated, the results showed that the workers remained on the average four hours a day in the same space of production during the journey work, mainly for feeding facilities and cleaning, and on the other half of the time they work in activities as feed transport and internal dislocations. The Effective Temperature values
\end{abstract}


stayed between the limits predicts for the workers $\left(18.9^{\circ} \mathrm{C}\right.$ to $\left.25.6^{\circ} \mathrm{C}\right)$ and the tolerance to the heat measured for Wet Bulb and Temperature of Globe (WBTG) was not exceeded in the most unfavorable period of the working day according to Brazilian Codes.

Keywords: Environmental factors. Worker. Housing. Swine.

\section{Introdução}

As atividades laborais relacionadas à produção animal carecem de informações. Muito se avalia se o ambiente térmico é favorável ao animal, entretanto, nessas atividades os trabalhadores podem sofrer fadiga em consequência do estresse térmico. Uma abordagem sobre o assunto é relevante para se compreender as condições qualitativas ambientais para os trabalhadores.

Estudo realizado por Ogilvie (1997) nos Estados Unidos mostrou que os trabalhadores podem permanecer de 4 a 8 horas/dia no mesmo espaço de produção animal.

O trabalho em condições climáticas desfavoráveis produz fadiga, extenuação física e nervosa, diminuição do rendimento, aumento nos erros e riscos de acidentes, além de expor o organismo a diversas doenças (COUTO, 1987). Estas consequências da atividade laboral são fruto do tempo de permanência do trabalhador no local de trabalho e das atividades por ele realizadas.

De acordo com Iida (1990), o conforto térmico para o ser humano é delimitado pelas temperaturas entre $20{ }^{\circ} \mathrm{C}$ e $24{ }^{\circ} \mathrm{C}$, com umidade relativa de $40 \%$ a $60 \%$ e velocidade do ar $0,7 \mathrm{~m} \cdot \mathrm{s}^{-1}$. Acima de $30{ }^{\circ} \mathrm{C}$ aumenta o risco de danos à saúde, as pausas tornam maiores e mais frequentes, o grau de concentração diminui e a frequência de erros e acidentes tende a aumentar significativamente. A Tabela 1 mostra a sensação térmica do corpo humano em função da temperatura e umidade relativa do ar, em que se constata que a uma temperatura de $35^{\circ} \mathrm{C}$ e umidade de $70 \%$, a sensação térmica é de $42,2{ }^{\circ} \mathrm{C}$, bem acima da temperatura homeotérmica do homem.

Tabela 1 - Sensação do organismo humano em função da umidade relativa do ar

\begin{tabular}{ccccccc}
\hline & \multicolumn{7}{c}{ Umidade relativa do ar (\%) } \\
\cline { 2 - 7 } Temperatura $\left({ }^{\circ} \mathbf{C}\right)$ & $\mathbf{3 0}$ & $\mathbf{5 0}$ & $\mathbf{7 0}$ & $\mathbf{8 0}$ & $\mathbf{9 0}$ & $\mathbf{1 0 0}$ \\
\hline 20 & 20,0 & 21,1 & 22,2 & 22,8 & 23,4 & 23,9 \\
25 & 25,0 & 26,7 & 27,8 & 28,9 & 30,0 & 31,1 \\
30 & 30,0 & 32,2 & 35,0 & 37,2 & 37,8 & 39,4 \\
35 & 35,0 & 38,8 & 42,2 & 44,4 & 46,7 & 48,9 \\
40 & 40,0 & 45,0 & 50,0 & & & \\
\hline
\end{tabular}

Fonte: Adaptado de GARCÍA, 1995.

O índice de Temperatura Efetiva é muito utilizado como indicador do estresse térmico sobre o corpo humano (GOMES; AMORIM, 2003), sendo usado nas regiões tropicais por se apresentar eficiente. Thom (1959) definiu como limites de conforto térmico os valores de Temperaturas Efetivas entre $18,9^{\circ} \mathrm{C}$ e $25,6{ }^{\circ} \mathrm{C}$. O corpo humano, ou seja, pessoas adultas vestidas em repouso e com um leve movimento do ar, apresenta condição de estresse ao frio sob Temperaturas Efetivas abaixo de $18,9^{\circ} \mathrm{C}$ e condição de estresse ao calor acima de $25,6^{\circ} \mathrm{C}$. 
O índice de Bulbo Úmido e Temperatura de Globo (IBUTG) é outro indicador do desconforto térmico e que é utilizado pela legislação brasileira (Lei n. 6.514, 1977; NR-15/Anexo 3 do Ministério do Trabalho e Emprego, 1978). É empregado para indicar a exposição ao calor em regime de trabalho intermitente com períodos de descanso no próprio local de prestação de serviço, não sendo permitido trabalho sem a adoção de medidas adequadas de controle para o IBUTG acima de $32,2^{\circ} \mathrm{C}$ em atividade leve, acima de $31,1{ }^{\circ} \mathrm{C} \mathrm{em}$ atividade moderada, e acima de 30,0 C em atividade pesada (trabalho intermitente de levantar, empurrar ou arrastar pesos), medido no período mais desfavorável do ciclo do trabalho.

Os objetivos deste trabalho foram medir o tempo médio de permanência do trabalhador em instalações para suínos e avaliar se as situações de conforto térmico para ele estão nos limites propostos pelos índices de Temperatura Efetiva e de Bulbo Úmido e Temperatura de Globo.

\section{Materiais e métodos}

Este trabalho foi realizado em instalações de creche e terminação de suínos de duas granjas típicas de produção (Granja 1 - Creche/G1c e Terminação/G1t; Granja 2 - Creche/G 2c e Terminação/G 2t), localizadas na região de Salto, SP, que possui latitude de $23^{\circ} 12^{\prime} 10^{\prime \prime}$ Sul, longitude $47^{\circ} 17^{\prime} 35^{\prime \prime}$ Oeste e altitude média de 521 m, correspondendo na classificação de Köppen (1900) como Cwa, ou seja, quente, temperado chuvoso, com estação seca no inverno e com verão quente. A região apresenta uma temperatura média anual de $26^{\circ} \mathrm{C}$, com ventos predominantes da direção noroeste em relação às instalações avaliadas.

As instalações se localizavam com orientação leste-oeste e foram avaliadas duas instalações de creche e duas de terminação, discriminadas a seguir. As anotações dos tempos laborais, das temperaturas diárias e da umidade do ar foram realizadas no verão e inverno de 2003.

A instalação para Creche correspondendo à Granja 1/G1c possuía altura no beiral de 2,30 m, telhado de duas águas com lanternim e cobertura de telhas de fibrocimento e era formada por quatro salas com área de piso de $173,00 \mathrm{~m}^{2}\left(0,48 \mathrm{~m}^{2}\right.$ /animal $)$ e cortina para controle ambiental. A limpeza era feita diariamente pela manhã com raspagem e lavação do piso e cada sala alojava em média 360 leitões.

A instalação para Creche correspondendo à Granja 2/G2c possuía pé-direito no beiral de 2,35 m, telhado de duas águas com lanternim e cobertura de telhas de barro e era formada por três salas com área de piso de $61,25 \mathrm{~m}^{2}\left(0,36 \mathrm{~m}^{2}\right.$ /animal $)$ e cortina para controle ambiental. A limpeza feita diariamente pela manhã com raspagem e lavação do piso e cada sala alojava em média 140 leitões.

A instalação para Terminação correspondendo à Granja 1/G1t e a Granja 2/G2t possuíam em comum telhado de duas águas com telhas de fibrocimento, altura no beiral de 2,00 $\mathrm{m}$ na G1t e de 3,20 $\mathrm{m}$ na G2t. A G1t era formada por oito baias com área de piso de $324,00 \mathrm{~m}^{2}\left(1,62 \mathrm{~m}^{2}\right.$ /animal), e cada baia alojava 200 animais em média. A limpeza nas instalações era feita diariamente, pela manhã, com raspagem e lavação do piso. A G2t era formada por 49 baias com área de piso de $24,20 \mathrm{~m}^{2}\left(0,97 \mathrm{~m}^{2} /\right.$ animal $)$ e cortina para controle ambiental, e a limpeza das baias consistia no esgotamento da lâmina de água realizada uma vez na semana e cada baia alojava 25 animais em média.

$\mathrm{Na}$ Granja 1, G1c e G1t, o arraçoamento era manual nos seguintes horários: 7h15, 9h, 10h30, 12h30, 15h e 16h30. Na Granja G2c o arraçoamento era manual e nos seguintes horários: 7h15, 9h, 10h30, 12h, 15h e 16h, e na G2t, 7h15, 10h, $12 \mathrm{~h} 30$ e às $16 \mathrm{~h}$.

O arraçoamento e a limpeza serviram de base para contagem do tempo das atividades laborais dentro das instalações.

As temperaturas de bulbo seco, bulbo úmido e de globo negro e a umidade relativa do ar foram obtidas em intervalos de 30 minutos utilizando um Monitor de Estresse Térmico da marca Questemp ${ }^{\circledR}$. As velocidades de vento interno $\left(V_{\text {int }}\right)$ e externo $\left(V_{\text {ext }}\right)$, as temperaturas e a umidade relativa do ar externas foram obtidas em intervalos de 30 minutos utilizando um Higrotermoanemômetro HTA da marca Pacer ${ }^{\circledR}$. Os instrumentos foram posicionados na altura de 1,50 m do piso, no ponto geométrico central das instalações.

Utilizaram-se os Índices de TE e de IBUTG para avaliação do ambiente de trabalho. O delineamento experimental foi em fatorial $2 \times 4 \times 6$ representando as estações (E: verão, inverno), as instalações 
(G1c, G2c, G1t e G2t) e os intervalos horários (H: 7h-8h, 8h30-9h30, 9h30-10h30, 11h30-12h30, 14h30$15 \mathrm{~h} 30$ e 16h-17h) e três repetições (dias). Para análise de variância foi empregado o teste "F" e as médias comparadas pelo teste de Tukey a 5\% de significância, utilizando o programa Statistical Analysis System $\mathrm{SAS}^{\circledR}$.

\section{Resultados}

A Tabela 2 mostra os valores das TE nos horários de arraçoamento.

Tabela 2 - Valores de Temperatura Efetiva $\left({ }^{\circ} \mathrm{C}\right)$ nos horários de arraçoamento

\begin{tabular}{|c|c|c|c|c|}
\hline \multirow{3}{*}{ Horários } & \multicolumn{4}{|c|}{ Local de trabalho: instalações para Creche } \\
\hline & \multicolumn{2}{|c|}{ Verão } & \multicolumn{2}{|c|}{ Inverno } \\
\hline & G1c & G2c & G1c & G2c \\
\hline $7 \mathrm{~h}-8 \mathrm{~h}$ & 23,3 & 23,2 & 17,8 & 21,5 \\
\hline $8 h 30-9 h 30$ & 23,5 & 22,6 & 18,4 & 19,6 \\
\hline $9 h 30-10 h 30$ & 23,9 & 23,2 & 19,2 & 21,4 \\
\hline $11 \mathrm{~h} 30-12 \mathrm{~h} 30$ & 24,8 & 24,3 & 20,5 & 22,5 \\
\hline $14 h 30-15 h 30$ & 26,0 & 24,8 & 21,0 & 24,0 \\
\hline \multirow[t]{2}{*}{ 16h-17h } & 25,3 & 24,4 & 21,0 & 23,7 \\
\hline & \multicolumn{4}{|c|}{ Local de trabalho: instalações para Terminaçã } \\
\hline \multirow[t]{2}{*}{ Horários } & \multicolumn{2}{|c|}{ Verão } & \multicolumn{2}{|c|}{ Inverno } \\
\hline & G1t & G2t & G1t & G2t \\
\hline $7 \mathrm{~h}-8 \mathrm{~h}$ & 20,9 & 18,1 & 17,6 & 14,3 \\
\hline 8 h30-9h30 & 22,0 & 20,4 & 20,1 & 16,1 \\
\hline $9 h 30-10 h 30$ & 22,7 & 21,9 & 21,1 & 18,1 \\
\hline $11 \mathrm{~h} 30-12 \mathrm{~h} 30$ & 24,6 & 23,1 & 22,3 & 21,5 \\
\hline $14 \mathrm{~h} 30-15 \mathrm{~h} 30$ & 25,8 & 24,0 & 22,8 & 22,7 \\
\hline 16h-17h & 24,7 & 23,7 & 21,7 & 22,2 \\
\hline
\end{tabular}

Fonte: Dados da pesquisa.

$\mathrm{Na}$ análise de variância, verificou-se que a estação do ano $(\mathrm{E})$, instalações $(\mathrm{G})$ e os horários $(\mathrm{H})$ tiveram influência significativa sobre os valores obtidos para IBUTG (Tabela 3).

O comportamento diário nos três dias de monitoramento do IBUTG pode ser visualizado nas Figuras 1 e 2.

Rev. Acad., Ciênc. Agrár. Ambient., Curitiba, v. 8, n. 4, p. 487-493, out./dez. 2010 
Tabela 3 - Resultados de comparação de médias para IBUTG

\begin{tabular}{|c|c|c|c|c|}
\hline \multirow{2}{*}{ Horas } & \multicolumn{2}{|c|}{ Verão } & \multicolumn{2}{|c|}{ Inverno } \\
\hline & G1 & G2 & G1 & G2 \\
\hline \multicolumn{5}{|c|}{ Local de trabalho: instalações para Creche } \\
\hline $7 \mathrm{~h}-8 \mathrm{~h}$ & $22,9 \mathrm{a}$ & $22,7 \mathrm{a}$ & $15,8 \mathrm{a}$ & $19,8 \mathrm{~b}$ \\
\hline $8 \mathrm{~h} 30-9 \mathrm{~h} 30$ & $23,2 \mathrm{a}$ & $22,0 \mathrm{a}$ & 16,4 a & $17,9 \mathrm{a}$ \\
\hline $9 \mathrm{~h} 30-10 \mathrm{~h} 30$ & $23,7 \mathrm{a}$ & 22,6 a & 17,3 a & $19,9 \mathrm{a}$ \\
\hline $11 \mathrm{~h} 30-12 \mathrm{~h} 30$ & $24,6 \mathrm{a}$ & $23,8 \mathrm{a}$ & $18,7 \mathrm{a}$ & $20,7 \mathrm{a}$ \\
\hline $14 h 30-15 h 30$ & $25,7 \mathrm{a}$ & 24,6 a & 19,2 a & $22,1 \mathrm{~b}$ \\
\hline $16 \mathrm{~h}-17 \mathrm{~h}$ & $25,2 \mathrm{a}$ & $23,8 \mathrm{a}$ & 19,3 a & $21,9 \mathrm{a}$ \\
\hline \multicolumn{5}{|c|}{ Local de trabalho: instalações para Terminação } \\
\hline $7 \mathrm{~h}-8 \mathrm{~h}$ & $20,0 \mathrm{a}$ & $16,4 \mathrm{~b}$ & 15,8 a & $11,7 \mathrm{~b}$ \\
\hline $8 \mathrm{~h} 30-9 \mathrm{~h} 30$ & $21,2 \mathrm{a}$ & $18,9 \mathrm{a}$ & $18,9 \mathrm{a}$ & $13,8 \mathrm{~b}$ \\
\hline $9 \mathrm{~h} 30-10 \mathrm{~h} 30$ & $21,9 \mathrm{a}$ & 20,6 a & $20,2 \mathrm{a}$ & $16,1 \mathrm{~b}$ \\
\hline $11 \mathrm{~h} 30-12 \mathrm{~h} 30$ & $24,0 \mathrm{a}$ & $21,9 \mathrm{a}$ & $21,5 \mathrm{a}$ & $19,8 \mathrm{a}$ \\
\hline 14h30-15h30 & $24,6 \mathrm{a}$ & $22,7 \mathrm{a}$ & 20,9 a & $21,0 \mathrm{a}$ \\
\hline $16 \mathrm{~h}-17 \mathrm{~h}$ & $24,0 \mathrm{a}$ & $22,8 \mathrm{a}$ & $20,1 \mathrm{a}$ & $20,4 \mathrm{a}$ \\
\hline
\end{tabular}

Nota: Letras iguais na linha não diferem pelo teste de Tukey ao nível de 5\% de probabilidade. Fonte: Dados da pesquisa.

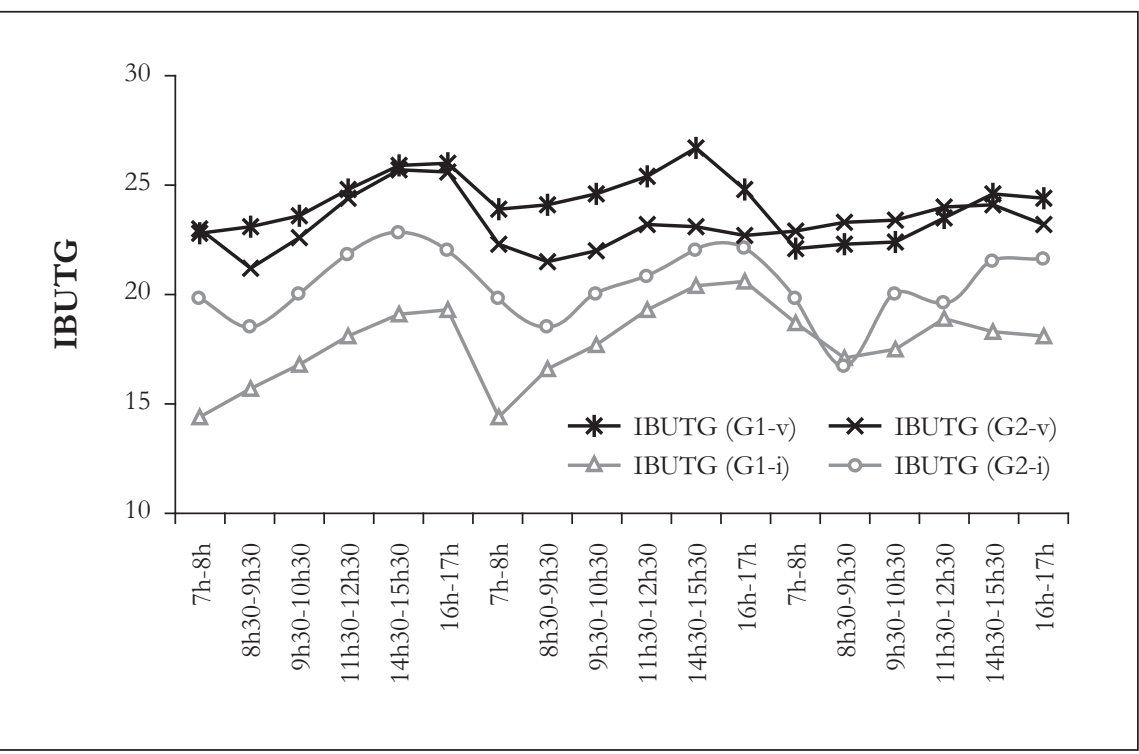

Figura 1 - Valores médios de IBUTG nas Creches, no verão (v) e no inverno (i) Fonte: Dados da pesquisa.

Rev. Acad., Ciênc. Agrár. Ambient., Curitiba, v. 8, n. 4, p. 487-493, out./dez. 2010 


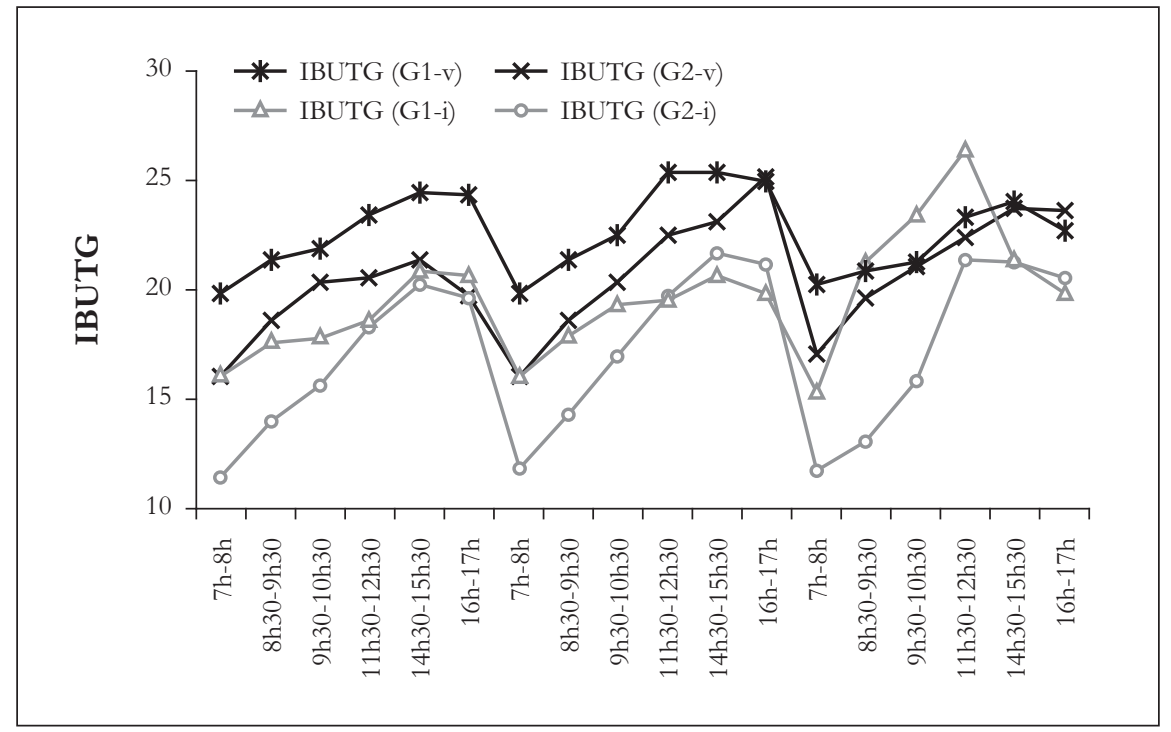

Figura 2 - Valores médios de IBUTG nas Terminações, no verão (v) e no inverno (i) Fonte: Dados da pesquisa.

\section{Discussão}

De acordo com a Tabela 2, nota-se que nos intervalos horários admitidos e que correspondem aos horários em que se realiza o arraçoamento, os índices ficaram no intervalo de conforto térmico proposto por Thom (1959).

De acordo com a Tabela 3, nas instalações de creche, tanto na G1c quanto na G2c, basicamente não se constatou diferenças significativas para IBUTG. Na Terminação, somente no inverno houve diferenças significativas com os menores valores na G2t, fato que pode ser atribuído ao material de cobertura. O IBUTG adotado pela legislação brasileira para determinar os limites de tolerância baseia-se no estabelecimento de determinado valor, abaixo do qual haverá pouca possibilidade de danos à saúde do trabalhador e, acima dele, essa chance torna-se maior (COUTO, 1987). Considerando atividade pesada no período mais desfavorável do ciclo do trabalho, entre 11h e 16h, o limite de tolerância ao calor não foi ultrapassado conforme estabelecidos pela NR-15.

Como se pode notar nas Figuras 1 e 2, o IBUTG apresentou aumento crescente das $7 \mathrm{~h}$ às $15 \mathrm{~h}$, com declínio após este horário, com os valores máximos ocorrendo entre $14 \mathrm{~h} 30$ e 15h30, com aclive até as $12 \mathrm{~h} 30$ e declive mais acentuado após as 15h30. A instalação G1c apresentou a maior amplitude de IBUTG entre os períodos de verão e inverno, graças às características do material de cobertura e ao número de animais por sala e ao manejo das cortinas, o que não ocorreu nas instalações para terminação, por serem mais abertas e de pé-direito elevado. A instalação da G1 apresentou os valores mais altos de IBUTG, tanto no verão como no inverno, graças principalmente às características do material de cobertura e construtivas.

Embora possa haver alterações durante a jornada de trabalho em virtude de causas que não sejam arraçoamento e limpeza das baias, constatou-se por anotações simples que os trabalhadores permaneciam em média 4 horas/dia no mesmo espaço de produção, direcionando a outra metade do tempo para atividades de buscar ração e deslocamentos internos, concordando com o que constatou Ogilvie (1997) nas instalações dos EUA.

\section{Conclusões}

A Temperatura Efetiva ficou no intervalo de conforto térmico, ou seja, entre $18,9{ }^{\circ} \mathrm{C}$ e $25,6{ }^{\circ} \mathrm{C}$. O IBUTG se manteve nos limites recomendados pela NR-15, que é de $30^{\circ} \mathrm{C}$ para atividade pesada (trabalho 
intermitente de levantar, empurrar ou arrastar pesos), no período mais desfavorável do ciclo do trabalho. O tempo de permanência do trabalhador dentro das instalações, tomando por base a limpeza das baias e o tempo de arraçoamento, foi em média de 4 horas/dia.

\section{Referências}

BRASIL. Lei 6.514, 22 de dezembro de 1977. Altera o Capítulo V do Titulo II da Consolidação das Leis do Trabalho, relativo à segurança e medicina do trabalho e dá outras providências. Diário Oficial [da] República Federativa do Brasil, Brasília, 1977. Disponível em: <http://www3.dataprev.gov.br/sislex/paginas/42/1977/6514.htm>. Acesso em: 20 dez. 2009.

BRASIL. Ministério do Trabalho e Emprego. Portaria 3.214 de julho de 1978. Normas regulamentadoras de segurança e saúde no trabalho - NR-15: Atividades e Operações Insalubres. Diário Oficial [da] República Federativa do Brasil, Brasília, 1978. Disponível em: <www.mte.gov.br/temas/segsau/legislacao>. Acesso em: 20 dez. 2009.

COUTO, H. A. Temas de saúde ocupacional: coletânea dos cadernos da Ergo. Belo Horizonte: Ed. Ergo, 1987.

GARCÍA, F. F. Manual de climatología aplicada: clima, medio ambiente y planificación. Madrid: Editorial Síntesis S.A., 1995.

GOMES, M. A. S.; AMORIM, M. C. C. T. Arborização e conforto térmico no espaço urbano: estudo de caso nas praças públicas de Presidente Prudente (SP). Caminhos de Geografia, v. 7, n. 10, p. 94-106, 2003.

IIDA, I. Ergonomia: projeto e produção. São Paulo: Edgard Blucher, 1990.

KÖPPEN, W. P. Classificação climática de Köppen. 1900. Disponível em: <http://pt.wikipedia.org>. Acesso em: 20 dez. 2009.

OGILVIE, J. R. Environmental systems: design and performance standard. In: INTERNATIONAL LIVESTOCK ENVIRONMENT SYMPOSIUM, 5., 1997, Bloomington, Minnesota. Proceedings... Bloomington, Minnesota: ASAE, St Joseph, 1997. p. 7-14.

THOM, E. C. The discomfort index. Weatherwise, v. 2, p. 57-60, 1959.

Recebido: 26/09/2010

Received: 09/26/2010

Aprovado: 04/11/2010

Approved: 11/04/2010

Rev. Acad., Ciênc. Agrár. Ambient., Curitiba, v. 8, n. 4, p. 487-493, out./dez. 2010 